\title{
DEVELOPING PERSONAS TO HELP DESIGNERS TO UNDERSTAND DIGITAL EXCLUSION
}

\author{
Goodman-Deane, Joy Ai-Leen; \\ Bradley, Mike; \\ Waller, Sam; \\ Clarkson, P. John \\ University of Cambridge
}

\begin{abstract}
Digital inclusion is becoming more important as many consumer products and engineered systems adopt increasingly digital interfaces. The designers of such services often assume that users have a certain level of digital interface competence, but this is not the case for many users. In this paper, we present a set of personas that could help designers to better understand and consider the range of digital expertise across the population. The personas are based on survey data from 338 people across England and Wales in 2019. The survey examined various factors that affect ability to use digital interfaces, including technology experience, attitudes towards technology and competence with basic interface operations. Twelve clusters were identified using K-means cluster analysis, and twelve personas were developed based on these. The personas help to bring to life the range of digital expertise and highlight people at risk of digital exclusion. In addition, the cluster sizes indicate the proportion of the population represented by each persona and thus the scale of potential digital exclusion.
\end{abstract}

Keywords: Inclusive design, Design methods, User centred design, Digital exclusion, Personas

\author{
Contact: \\ Goodman-Deane, Joy Ai-Leen \\ University of Cambridge \\ Engineering \\ United Kingdom \\ jag76@cam.ac.uk
}

Cite this article: Goodman-Deane, J. A.-L., Bradley, M., Waller, S., Clarkson, P. J. (2021) 'Developing Personas to Help Designers to Understand Digital Exclusion', in Proceedings of the International Conference on Engineering Design (ICED21), Gothenburg, Sweden, 16-20 August 2021. DOI:10.1017/pds.2021.120 


\section{INTRODUCTION}

Digital inclusion is becoming more important as many consumer products and engineered systems adopt increasingly digital interfaces. In addition, many services are moving online or include digital interface elements. The designers of such products and services often assume that the users will have a certain level of digital interface competence (Bradley et al., 2016). For example, they might use a symbol without explanatory text, assuming that users will know what it means (Bradley et al., 2011). However, not all users have the required levels of technology experience or competence. For example, Blank et al. (2019) found that large numbers of those over 65 reported not using the internet. Furthermore, the range of technology competence is broader and more varied than the headline figures about technology use suggest. For example, some people use the internet but do not own a smartphone. Others use smartphones, but do not download apps. Some people are happy to use a familiar interface but struggle with new ones.

It is critical that designers better understand the range of users' technology experience and competence. This would enable them to account for these factors when they design digital products, interfaces and services to ensure their solutions are inclusive.

In this paper, we present a set of personas that could help designers, engineers and developers to better understand and consider the range of digital expertise across the population. The personas are based on results from a survey conducted with 338 adults across England and Wales, examining a range of factors that affect an individual's ability to use digital interfaces. We explain how personas were developed from the survey results using cluster analysis to bring the range of digital expertise to life. The full set of personas is available for free at Engineering Design Centre (2020).

\section{BACKGROUND}

\subsection{Understanding digital exclusion}

Various previous surveys have examined technology access and experience. For example, the ONS Internet Access survey (Office for National Statistics, 2017) and the Global Attitudes Survey (Pew Research Center, 2017) asked survey participants about their access to technology, the frequency with which they use different kinds of technology and the types of activities they do on a computer. These are important aspects for considering whether someone will be able to use a new piece of technology. Lack of access is a key barrier to someone using a service, and technology experience has been shown to affect performance on similar interfaces (e.g. Blackler et al., 2010).

However, technology access and experience are not the only factors that affect ability to use a digital interface. There are many other factors including users' attitudes, ability to learn and cope with errors and other capabilities and skills (Wagner et al, 2010; Goodman-Deane et al, 2020b). It is important to understand how these are spread across the population and how they interact with each other in order to determine whether and how users will be able to use digital interfaces effectively. While there has been valuable work examining some of these aspects individually (e.g. Franke et al, 2019), less has been done to understand the range of relevant factors, particularly at a population level.

Another way to approach the issue is to examine technology competence directly. There have been various efforts to assess digital and ICT literacy skills in the population. For example, a large-scale survey conducted by the Organisation for Economic Co-operation and Development (OECD, 2016) assessed "the cognitive skills required to access and make use of computer-based information to solve problems". However, the tests involved relatively complex tasks with problem solving requirements and the results were banded into broad levels. This makes it difficult to determine participants' competency at the basic skills involved in using less complex interfaces. Furthermore, it was only administered to adults of working age (aged 16 to 65) and only "those respondents with some computer experience and facility" did the computer skills module. Other similar measures of digital literacy skills have been typically administered to students or school children (Ainley et al, 2016).

Some research has focused on designing measures of more basic technology competence, particularly for use with older adults. For example, Sengpiel and Dittberner (2008) examined knowledge of common computer symbols and terms. They found that this predicted performance on technology interfaces amongst older adults. Similarly, Hurtienne et al. (2013) measured basic technology competence using a symbol recognition test and self-report questions. They found that these predicted 
usability measures on an unfamiliar interface. However, to our knowledge, these measures have not been used within population-level surveys.

The survey described in this paper attempts to address this situation by including measures of a variety of factors that affect digital competence, including competence on basic technology tasks, as well as access, experience and attitudes.

\subsection{Using personas to help understanding of digital exclusion}

In this paper, personas are used to capture the range of technology experience and competence in the population. Personas are fictional profiles of users that help designers to understand and consider the needs of target users during the design process. They were introduced to design by Cooper (1999) who used personas to represent the patterns found in qualitative research.

Despite their popularity, some authors have expressed concerns over the representativeness of basing personas on qualitative research, particularly when examining heterogeneous groups, such as older adults (e.g. Wöckl et al., 2012). As a result, some have proposed developing personas based on largerscale or even population-level survey data using statistical techniques (e.g. Brickey et al., 2010; Wöckl et al., 2012). This approach is particularly important in inclusive design, where capturing the diversity across the population is crucial (González de Heredia et al., 2018).

While some quantitative personas have been developed for supporting inclusive design, these have often focused on particular groups at risk of exclusion, such as older people (e.g. Reeder et al, 2011; Wöckl et al., 2012). As far as we are aware, there has been little work on creating a set of quantitative personas that represent the whole population for use in inclusive design.

\section{SURVEY}

The personas in this paper are based on results from a survey of 338 people aged 16 and over in England and Wales carried out in June-July 2019. The survey was developed by the authors and conducted by Cambridge Market Research, an independent market research company. Participants completed a 20-minute questionnaire with an interviewer using a CAPI (Computer-Assisted Personal Interviewing) system. Approval was obtained from the University of Cambridge Engineering Department ethics committee. Initial results from the survey can be found in Goodman-Deane et al (2020a).

\subsection{Sample}

Quota sampling was used to match the sample to UK census 2011 data (Office for National Statistics, 2011) for gender, age, social grade and (more roughly) education. Social grade was classified using the National Readership Survey (undated) classification. A quota was also set on technology use (internet use on a mobile device) based on data from Ofcom (2018) and Pew Research Center (2017).

Participants were recruited in two ways. 328 participants were recruited on-street using a screening questionnaire. They were given a $£ 10$ high street shopping voucher for their participation. On-street recruitment accesses a wide range of people but under-samples those who do not leave the house frequently. Therefore, an additional ten interviews were conducted with participants who reported that they left the house once a week or less. They received $£ 20$ in cash for taking part.

The resultant sample was $51 \%$ female, $49 \%$ male and $0 \%$ other. The age distribution was: 16-24 (15\%), 25-34 (16\%), 35-44 (15\%), 45-54 (17\%), 55-64 (14\%), 65+ (24\%). 25\% of the sample was in social grades $\mathrm{AB}, 35 \%$ in grade $\mathrm{C} 1,16 \%$ in grade $\mathrm{C} 2$ and $23 \%$ in grades DE. These match the quotas well. The sample was a little low on those with no education (16\%). The results were then weighted to match the levels reported in the UK 2011 census in three categories: no educational qualifications, levels 1-3/apprenticeship and level 4 and above.

\subsection{Questionnaire}

The questionnaire covered the following aspects: technology access and use, technology activities, attitudes towards technology, technology competence, sensory, motor and cognitive capabilities and demographics. The questions of most relevance to the personas are described briefly below.

Questions on technology experience were adapted from those in Office for National Statistics (2017) with the addition of similar questions about mobile phone, smartphone and tablet use. Participants were asked about the frequency with which they used various technologies. They were then asked 
whether they had carried out certain technology activities in the last three months. There were also asked about other technology activities that may occur less frequently over a longer time period (12 months). These questions were also adapted from ones in Office for National Statistics (2017), with some activities added to investigate topics of particular interest. The activities used in the analysis in this paper are: e-mail, video/voice internet calls, social networking, online news, internet search, finding out about goods/services online, buying goods/services online, internet banking, booking travel, using mapping applications, copying/moving a file/folder, transferring files between devices, installing software on a computer, installing an app on a tablet/ smartphone, changing settings, wordprocessing, editing photos etc and writing computer code.

Attitudes towards technology were examined using the Affinity for Technology Interaction scale (ATI) developed by Franke et al. (2018). Additional Likert style questions were developed by the authors to examine concepts such as willingness to explore an interface.

Basic technology competence was assessed using eight simplified paper prototype tests. Participants were shown images of smartphone interfaces on paper showcards (such as the one in Figure 1). They were then asked to indicate what they would do to achieve a particular goal, e.g. change the settings, such as the colours used in the calendar in Figure 1. Participants indicated just the first action that they would do, pointing to the appropriate place on the showcard. The interviewer coded their responses into pre-determined options to increase consistency in recording. This simplified paper prototyping method was used to avoid lengthy interviewer training and to keep the length of the interviews down. This lower cost approach enabled a larger sample size. The tests examined the following tasks: search, changing settings, creating a new event, opening a menu with more options, going back to a previous screen, activating a drop-down menu, activating an on-screen keyboard and setting favourites.

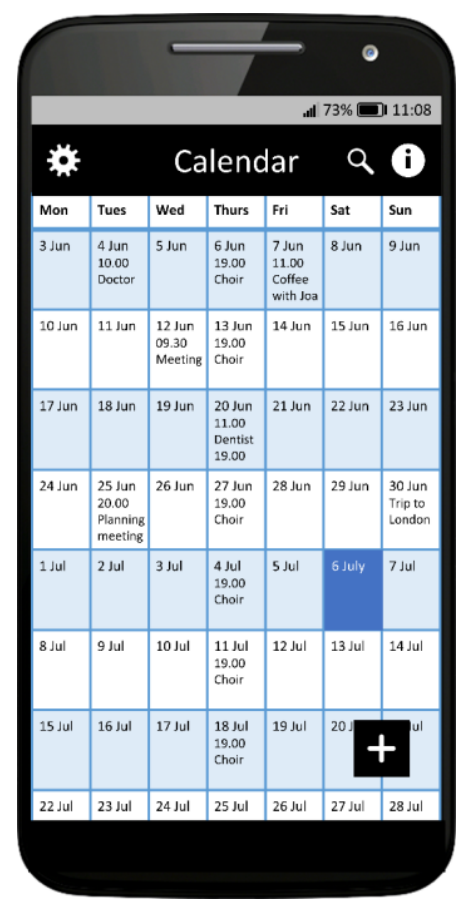

Figure 1. Example of an interface used in the digital competence tests in the survey

\section{PERSONAS}

\subsection{Cluster analysis}

A K-means cluster analysis was carried out on the survey results using five clustering variables. These variables were calculated from participants' responses to summarise their results in various areas related to digital exclusion:

- Technology experience: The number of technologies used on a daily basis out of a possible total of four: computer, internet, smartphone and tablet.

- Technology activities: The number of technology activities they reported doing out of a possible total of 18 . 
- $\quad$ ATI: The participant's Affinity for Technology Interaction (ATI) score (Franke et al., 2018). This score examines "a person's tendency to actively engage in intensive technology interaction". It is related to successful coping with technology.

- Willingness to explore an unfamiliar interface: Participants were asked how much they agreed with the following two statements. Their responses to the latter were reversed, and the mean of the two values was taken.

- When I'm not sure what to do next on a technical system, I try out different things until something works.

- I am uneasy about tapping or clicking on things that I don't recognise in case something breaks.

- Technology competence: The total number of technology competence tests done correctly, out of a possible total of eight.

The cluster analysis was conducted with different numbers of clusters to identify the smallest number of clusters with an acceptably small amount of variation within each cluster. The variation was deemed to be acceptable if the mean square of the error for each variable was less than or equal to one scale point or 1/10th of the scale whichever was larger. Using this analysis, twelve clusters were chosen, as shown in Figure 2.

\begin{tabular}{|c|c|c|c|c|c|c|}
\hline \multirow{2}{*}{ Persona } & \multirow{2}{*}{$\begin{array}{l}\text { Cluster } \\
\text { size }\end{array}$} & \multirow{2}{*}{$\begin{array}{l}\text { Competence } \\
\text { with } \\
\text { technology }\end{array}$} & \multicolumn{2}{|c|}{$\begin{array}{l}\text { Use of } \\
\text { technology }\end{array}$} & \multicolumn{2}{|c|}{$\begin{array}{l}\text { Attitudes to } \\
\text { technology }\end{array}$} \\
\hline & & & $\begin{array}{l}\text { Frequency } \\
\text { of use }\end{array}$ & $\begin{array}{l}\text { Range of } \\
\text { activities }\end{array}$ & $\begin{array}{c}\text { Desire to } \\
\text { engage }\end{array}$ & $\begin{array}{l}\text { Willingness } \\
\text { to explore }\end{array}$ \\
\hline Derek & $12 \%$ & $\begin{array}{l}\text { Very low } \\
(0.5)\end{array}$ & Very low & Very low & Very low & Very low \\
\hline Joshua & $3 \%$ & $\begin{array}{l}\text { Very low } \\
(2.0)\end{array}$ & Very high & Moderate & Moderate & Low \\
\hline Ida & $8 \%$ & $\begin{array}{l}\text { Very low } \\
(2.5)\end{array}$ & Very low & Very low & Low & Moderate \\
\hline William & $9 \%$ & $\begin{array}{l}\text { Low } \\
(4.0)\end{array}$ & Low & Low & Low & Low \\
\hline Nancy & $6 \%$ & $\begin{array}{l}\text { Low } \\
(4.0)\end{array}$ & High & Moderate & Low & High \\
\hline Maria & $6 \%$ & $\begin{array}{l}\text { Low } \\
(4.5)\end{array}$ & Very high & Very high & High & High \\
\hline Kamal & $7 \%$ & $\begin{array}{l}\text { Moderate } \\
\quad(6.0)\end{array}$ & High & Moderate & Low & Low \\
\hline Anna & $14 \%$ & $\begin{array}{l}\text { Moderate } \\
\quad(6.5)\end{array}$ & High & High & Moderate & High \\
\hline Robert & $2 \%$ & $\begin{array}{l}\text { High } \\
(7.0)\end{array}$ & Very low & Very low & Low & Moderate \\
\hline Laura & $8 \%$ & $\begin{array}{l}\text { High } \\
(7.0)\end{array}$ & High & Low & Low & High \\
\hline Eric & $9 \%$ & $\begin{array}{l}\text { High } \\
(7.5)\end{array}$ & Very high & Very high & High & Moderate \\
\hline Sam & $16 \%$ & $\begin{array}{l}\text { High } \\
(7.5)\end{array}$ & Very high & Very high & High & Very high \\
\hline
\end{tabular}

Figure 2. Summary of the distribution of the key variables across the persona set. This table is available online at Engineering Design Centre (2020). 


\subsection{Creating personas to represent the clusters}

A persona was developed for each of the twelve clusters, corresponding to a point as close to the centre of the corresponding cluster as possible. To achieve this, the values chosen for the five clustering variables were as close to the cluster means for those variables as possible (given the need for rounding). The results are shown in Figure 2. Rather than giving exact values for the variables, they are banded into five bands: Very low, Low, Moderate, High and Very high. This was done to make the values easier to interpret for the target users of the personas (designers, etc), who are unlikely to be familiar with the underlying variables and what they mean. Note that technology competence does not have a Very high level. This is because the technology competence tests were all fairly easy. Getting all the tests right does not necessarily indicate a Very high level of technology competence.

For each persona, text descriptions were written about each of the three categories shown in Figure 2: Competence with technology, Use of technology and Attitudes to technology. An example can be seen in Figure 3. These text descriptions help to bring the headline figures to life and describe how the persona relates to technology within their daily lives. They were chosen based on the distribution of detailed variables within the cluster (such as the frequency of computer use and the specific technology activities done) and to be consistent with the rest of the persona description (see Section 4.3).

For example, in Figure 3, Ida has a Very low frequency of technology use and Very low range of technology activities. This is explained further in the text description as follows: Ida "has used a computer occasionally in the past, mostly for communicating with work. However, she does not own her own computer and only occasionally uses one now. The only times she used one in the last few months was to look up some information on a friend's computer. She owns an old smartphone that a friend passed on to her but only uses it to make calls and send text messages".

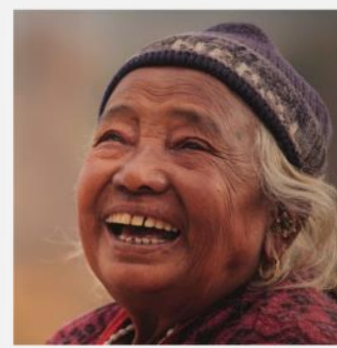

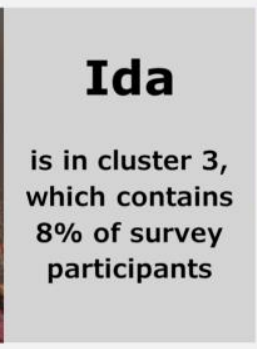
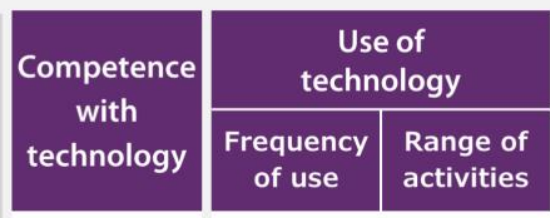

\section{Very low}

$(2.5 / 8)$

\section{Lifestyle}

Ida retired a few years ago from working in the kitchens at a local school. She lives alone and has no close family. However, she has many friends and is very involved in her local community - she belongs to a local church and gardening club and also volunteers at a charity shop once a week.

\section{Competence with technology}

Got three of the performance tests correct (out of eight), but she wasn't very sure about one of those.

\section{Use of technology}

Has used a computer occasionally in the past, mostly for

communicating with work. However, she does not own her own computer and only occasionally uses one now. The only times she used one in the last few months was to look up some information on a friend's computer. She owns an old smartphone that a friend passed on to her but only uses it to make calls and send text messages.

\section{Physical and sensory capabilities}

Recently had cataract surgery which has improved her eyesight, but still needs to use glasses for close work such as reading. Sometimes finds it hard to hear people in a crowded room.

\section{Attitudes to technology}

Not interested in new technology and would rather not engage with it if given the choice. Not very confident about her ability to use new technology or to recover from errors. If she is unsure what to do on an interface, she would try a few things to see what they do.

Figure 3. One of the personas in the resultant set. Note that this figure is intended to show the structure of a persona and that detailed text may not be legible. The full version of this and the other personas are available online at: Engineering Design Centre (2020). 


\subsection{Adding further contextual details to the personas}

Adding demographic and lifestyle information to personas is important for bringing them to life and helping designers to engage with them. This additional information was not involved in the cluster analysis, so it varies across the people in a cluster. Nevertheless, it is important that it fits with the people within the cluster.

This can be seen if we consider age as an example. Many of the clusters had a wide age range, such as cluster 8 which had a fairly even age distribution across many different age groups. As a result, we could not simply use the mean age of each cluster for the corresponding persona. This would result in almost all of the personas being aged between 30 and 60. This would not reflect the spread of ages either in individual clusters or in the dataset as a whole, and would work against our aim of encouraging designers to consider the diversity in the population.

Instead, the demographics of each persona were chosen to be appropriate to the corresponding cluster (to sit within the main range of demographics covered in that cluster) but also to ensure a good spread across the set of personas as a whole. Various demographic variables were considered including age, gender, social grade, education, ethnicity and life situation. Note that not all of these variables were gathered in the underlying survey. In these cases, the demographics were chosen to ensure a good range across the persona set.

An additional consideration was that technology competence was not correlated with gender in the survey (Goodman-Deane et al, 2020a). As a result, care was taken to ensure that there were both male and female personas in each of the bands of technology competence.

Once the demographic and lifestyle information had been chosen, its presentation was considered. Stock photographs were selected for each persona to match this information. In fact, the information was generally not given explicitly, but conveyed more implicitly in the choice of photographs and in the text descriptions of the personas' lifestyles. This can be seen in the example in Figure 3. This was done to encourage designers away from placing too much emphasis on the demographic information since it was not actually part of the underlying cluster analysis.

Information about sensory and physical capabilities was also included to encourage designers to consider the range of these in the population and to think about their impact on technology use. As with the demographic information, these were chosen based on the spread of capabilities within each cluster and to cover a range of different situations.

\subsection{Initial use of the personas}

An initial version of the personas was used by KAD (Keolis Amey Docklands), a train operating company. Seven internal presentations were held, for an average of one hour each, with engineers, safety managers and technical operational staff to help them to think about the user perspective. The sessions focused on two of the personas (Derek and Anna) to focus attention on particular needs. Derek was identified as the type of passenger that the passenger assistance team might meet and help in practice. Anna was chosen as an example of a fairly technically aware and independent traveller who nonetheless has some difficulties in some situations. The staff were encouraged to think about how these personas would use a proposed digital service and whether they would find it useful.

Feedback from the sessions indicates that the personas were effective in helping staff to identify issues that users might experience with the service. Staff were also encouraged to think about people in their lives that may have some of the issues the personas highlighted. It was felt that this increased levels of empathy and insight.

KAD is mature in its accessibility offering and work with the community, with considerable accessibility efforts and schemes targeted to remove barriers to travel. Despite this existing work and levels of awareness, KAD staff still reported that the personas were useful.

\section{Discussion}

\subsection{Understanding digital exclusion}

One of the main aims of this work was to help designers and other stakeholders to understand what causes digital exclusion, i.e. what affects whether an end user can or cannot use a digital interface. Furthermore, the aim was to enable them to understand how this varies across the population. This is 
important for considering and including the needs of a wider range of people in the design of digital products and services.

This study works towards this aim by providing data on multiple factors involved in digital exclusion including technology use, attitudes towards technology and direct measures of basic technology competence. This builds on previous work looking at these factors but provides additional valuable insight into how these factors intersect by gathering data on them together in a single survey.

The personas communicate the results of this to designers and other stakeholders in an accessible way. By basing the personas on a cluster analysis of the dataset, they represent the whole range of people across the population and show how the key variables group together. The personas are differentiated not just by their levels of technology competence, but also by their experience and their attitudes towards technology.

For example, Samantha and Eric are very similar personas with high levels of technology competence but they differ in one key variable: Samantha has a much higher willingness to explore an interface. This does not have much impact on the basic measures of technology competence used in the survey, but it could affect perseverance and performance on more complex or novel systems.

Furthermore, some of the personas highlight combinations of variables that are less expected. For example, Robert has a fairly high competence with technology, even though his use of technology and desire to engage with it is low. Conversely, Joshua uses technology a lot, yet his competence is very low. These clusters are small but not negligible. One of the advantages of a persona set based on cluster analysis is that these groups of people can be identified and highlighted while also indicating roughly how many people they represent in the population more widely. Even though the clusters are small, they serve as important reminders about the diversity in the population and warn designers against making generalisations.

\subsection{Unusual characteristics of the persona set}

The set of personas presented in this paper is unusual in various ways. Many existing persona sets are based on qualitative data or it is unclear what their basis is. Basing personas on quantitative data from across the population can ensure a better distribution of personas, as well as helping designers to understand how many people are affected by their design decisions.

Although other sets of quantitative personas for inclusive design exist, these mostly focus on particular groups at risk of exclusion. The set in this paper helps designers to understand the whole range of people across the population.

The set of personas is also relatively large. This is because the underlying analysis used five different clustering variables across the range of the population. More personas are needed to capture the diversity in a population if more variables are considered and if the population is broad rather than being restricted to particular age groups or characteristics. The large number of personas is important to help avoid stereotyping and to capture unusual combinations of variables.

However, we recognise that such a large set of personas may be too large to keep in mind during the design process. Design teams may choose to focus on a smaller number of personas that are more specific to their project or highlight needs that they would otherwise be inclined to forget. This is shown in the case study described in Section 4.4 where the team leads identified two of the personas that they wanted their teams to focus on for specific reasons.

\subsection{Limitations}

The set of personas is limited because the survey only included 338 people and is not fully population representative. Nevertheless, efforts were made to ensure that the survey was as representative as possible given its size, by using quota sampling on a variety of variables. Thus, it can still give a good indication of how the factors affecting digital exclusion vary across the population.

Another limitation is that paper prototype testing was employed rather than testing on real interfaces. This method does not replicate certain gestures, such as swiping and press and hold, very well. In addition, it does not allow the user to explore the interface and try out different actions. To help address this, we chose actions that could be achieved by a single tap of something that was visible on the screen at the time. Further work will examine how well these prototype tests correspond to performance on real interfaces.

The fast pace of technology change also presents an issue, as survey results rapidly become dated. Nevertheless, these personas can help designers to understand the current situation. Furthermore, the 
survey incorporates questions from other surveys that are conducted on a regular basis (e,g,. Office for National Statistics, 2017). It may be possible to use the data from new versions of these other surveys to examine how the aspects in this survey change over time.

\section{CONCUSIONS AND FURTHER WORK}

This paper describes the development of a set of twelve personas based on quantitative survey data. These personas help to bring to life a range of factors that affect digital exclusion, including technology use, attitudes towards technology and basic technology competence. This is helpful for designers and other stakeholders, to help them to understand and consider how these factors vary across the population. They also highlight people at risk of digital exclusion.

The survey work is currently being expanded to other countries in Europe to provide a wider picture of digital exclusion. These surveys will also gather more information on transport use, which could be used to expand the personas, especially for use in the design of digital transport services and products. Further work will also examine the use of these personas within a method for assessing how inclusive a particular digital interface is.

\section{ACKNOWLEDGEMENTS}

This work was part of a project to improve the inclusivity of railway journeys and information systems. It was funded by DFT and delivered through RSSB's TOC'16 project: Towards the Inclusive Railway. Collaborative partners were Siemens Mobility, Keolis Amey Docklands and Astutim. We would also like to thank the University of Cambridge Statistics Clinic, and particularly Sam Power, who provided valuable advice on the cluster analysis.

\section{REFERENCES}

Ainley, J., Schulz, W. and Fraillon, F. (2016), A global measure of digital and ICT literacy skills. UNESCO (United Nations Educations, Scientific and Cultural Organization), Paris. Available at: https://research.acer.edu.au/ict_literacy/12/ (accessed Nov 2020).

Blackler, A., Popovic, V. and Mahar, D. (2010), "Investigating users' intuitive interaction with complex artefacts". Applied Ergonomics, Vol. 41, pp. 72-92.

Blank, G., Dutton, W.H. and Lefkowitz, J. (2019), Perceived Threats to Privacy Online: The Internet in Britain. Oxford Internet Institute, Oxford. Available at: https://oxis.oii.ox.ac.uk/reports/ (accessed Nov 2020).

Bradley, M., Langdon, P. and Clarkson, P.J. (2011), "Older User Errors in Handheld Touchscreen Devices: To What Extent Is Prediction Possible?”, Universal Access in Human-Computer Interaction (UAHCI 2011), Orlando, FL, July 2011. Lecture Notes in Computer Science, Vol. 6766, Springer, pp. 131-139.

Bradley, M., Langdon, P., Clarkson, P.J. (2016), “An Inclusive Design Perspective on Automotive HMI Trends”, Universal Access in Human-Computer Interaction (UAHCI 2016), Toronto, July 2016. Lecture Notes in Computer Science, Vol. 9739, Springer, pp. 548-555.

Brickey, J., Walczak, S. and Burgess, T. (2010), "A Comparative Analysis of Persona Clustering Methods", AMCIS 2010. Lima, Peru, Aug 2010, AIS, Paper 217.

Cooper, A. (1999), The Inmates Are Running the Asylum, SAMS, Indianapolis, Indiana.

Engineering Design Centre (2020), Inclusive Design Toolkit: Digital personas. [online] Engineering Design Centre, University of Cambridge. Available at: www.inclusivedesigntoolkit.com/digitalpersonas (accessed: Dec 2020).

Franke, T., Attig, C. and Wessel, D. (2019), “A Personal Resource for Technology Interaction: Development and Validation of the Affinity for Technology Interaction (ATI) Scale”, International Journal of HumanComputer Interaction, Vol. 35, No. 6, pp. 456-467.

González de Heredia, A., Goodman-Deane, J., Waller, S., Clarkson, J., Justel, D., Iriarte, I., Hernández, J. (2018), "Personas for policy-making and healthcare design", International Design Conference - Design 2018. Dubrovnik, May 2018, The Design Society.

Goodman-Deane, J., Waller, S., Demin, D., González-de-Heredia, A., Bradley, M. and Clarkson, P.J. (2018), "Evaluating inclusivity using quantitative personas", DRS 2018: Design Research Society Conference 2018, Limerick, Ireland, June 2018, DRS, Vol. 5, pp. 1828-1840.

Goodman-Deane, J., Bradley, M. and Clarkson, P.J. (2020a), "Digital technology competence and experience in the UK population: who can do what", Ergonomics and Human Factors 2020, Apr 2020, Stratford-uponAvon, UK, CIEHF.

Goodman-Deane, J., Bradley, M., Waller, S., Clarkson, P.J. (2020b), “Quantifying exclusion for digital products and interfaces", CWUAAT 2020 (10th Cambridge Workshop on Universal Access and Assistive Technology), Cambridge, UK, March 2020, Springer. 
Hurtienne, J., Horn, A.-M., Langdon, P.M. and Clarkson, P.J. (2013), "Facets of prior experience and the effectiveness of inclusive design". Universal Access in the Information Society, Vol. 12, pp. 297-308.

National Readership Survey (undated), Social Grade. [online] National Readership Survey. Available at: http://www.nrs.co.uk/nrs-print/lifestyle-and-classification-data/social-grade/ (accessed Dec 2020).

OECD (2016), Skills Matter: Further results from the survey of adult skills, OECD, Available at: https://www.oecd.org/skills/skills-matter-9789264258051-en.htm (accessed Nov 2020).

Ofcom (2013), Communications Market Report, Ofcom, Available at: https://www.ofcom.org.uk/research-anddata/multi-sector-research/cmr/cmr13 (accessed Nov 2020).

Office for National Statistics (2011), 2011 Census. [online] Office for National Statistics. Available at: https://www.ons.gov.uk/census/2011census (accessed Dec 2020).

Office for National Statistics (2017), Internet Access - households and individuals, Great Britain: 2017. [online]. Office for National Statistics. Available at: https://www.ons.gov.uk/peoplepopulationandcommunity/householdcharacteristics/homeinternetandsocialm ediausage/bulletins/internetaccesshouseholdsandindividuals/2017 (accessed Nov 2020).

Pew Research Center (2017), Global Attitudes Survey 2017. [online] Pew Research Center, Available at: https://www.pewresearch.org/global/datasets (accessed Nov 2020).

Reeder, B., Zaslavksy, O., Wilamowska, K., Demiris, G. and Thompson, H. (2011), "Modeling the Oldest Old: Personas to Design Technology-Based Solutions for Older Adults, AMIA Annual Symposium Proceedings 2011, Washington, DC, Oct 2011, AMIA, pp. 1166-1175.

Sengpiel, M. and Dittberner, D. (2008), “The computer literacy scale (CLS) for older adults - development and validation", Mensch \& Computer, S. 7-16.

Wagner, N., Hassanein, K. and Head, M. (2010), "Computer use by older adults: A multi-disciplinary review”, Computers in Human Behavior, Vol. 26, pp. 870-882.

Wöckl, B., Yildizoglu, U., Buber, I., Aparicio Diaz, B., Kruijff, E. and Tscheligi, M. (2012), "Basic Senior Personas: A Representative Design Tool Covering the Spectrum of European Older Adults", ASSETS '12, Boulder, Colorado, Oct 2012. 